Proceedings

\title{
Does Vacuum Packaging Retain the Quality of Hilsa Fish (Tenualosa ilisha) during Long-Term Frozen Storage? ${ }^{\dagger}$
}

\author{
Sonia Khatun 1, Shaima Aktar 1, Zannatun Naeem 1, Md. Monjurul Hasan 2, Fawzia Adib Flowra ${ }^{1}$, \\ Md. Abul Bashar ${ }^{2}$, Md. Tariqul Islam ${ }^{1, *}$ and Yahia Mahmud ${ }^{3}$ \\ 1 Department of Fisheries, University of Rajshahi, Rajshahi 6205, Bangladesh; soniaru3828@gmail.com (S.K.); \\ shaimasb96@gmail.com (S.A.); zannatun896@gmail.com (Z.N.); flowrabd@yahoo.com (F.A.F.) \\ 2 Bangladesh Fisheries Research Institute, Riverine Station, Chandpur 3602, Bangladesh; \\ mhshihab.hasan@gmail.com (M.M.H.); mabashar.bfri@gmail.com (M.A.B.) \\ 3 Bangladesh Fisheries Research Institute, Headquarter, Mymensingh 2201, Bangladesh; \\ yahiamahmud@yahoo.com \\ * Correspondence: tariqrubd@gmail.com; Tel.: +880-171-269-7251 \\ + Presented at the 1st International Electronic Conference on Food Science and Functional Foods, \\ 10-25 November 2020; Available online: https://foods_2020.sciforum.net/.
}

Citation: Khatun, S.; Aktar, S.; Naeem, Z.; Hasan, M.; Flowra, F.A.; Bashar, A.; Islam, T.; Mahmud, Y.

Does Vacuum Packaging Retain the Quality of Hilsa Fish (Tenualosa ilisha) during Long-Term Frozen Storage? Proceedings 2021, 70, 60 . https://doi.org/10.3390/foods_2020-0 7621

Published: 9 November 2020

Publisher's Note: MDPI stays neutral with regard to jurisdictional claims in published maps and institutional affiliations.

Copyright: (c) 2020 by the authors. Licensee MDPI, Basel, Switzerland. This article is an open access article distributed under the terms and conditions of the Creative Commons Attribution (CC BY) license (http://creativecommons.org/licenses /by/4.0/).

\begin{abstract}
Long-term frozen storage deteriorates the quality of hilsa fish (Tenualosa ilisha), famous for its delicious taste and flavors. Vacuum packaging may retain the flavor and quality of hilsa fish. To this end, biochemical and microbiological analyses were used to assess the quality of hilsa fishes under whole without pack, whole with vacuum pack, dressed without pack, and dressed with vacuum pack, at a monthly interval during a year of frozen storage at $-18{ }^{\circ} \mathrm{C}$. There were no significant differences $(p>0.05)$ in the values of $\mathrm{pH}$, free fatty acids (FFA), total volatile base nitrogen (TVB-N), and aerobic plate count (APC) among the treatments, and the values remained within the acceptable limit during the storage period. However, thiobarbituric acid reactive substances (TBARS) were significantly $(p<0.05)$ lower in samples under vacuum (whole and dressed) compared to samples without pack. TBARS values did not cross the acceptable limit for vacuum pack samples in nearly the entire storage period but were exceeded for samples without pack within the first month. It is assumed that the vacuum packaging reduced the secondary oxidation of fatty fish like hilsa during the frozen storage, which can ensure a year-round supply of quality hilsa fish without altering its distinctive taste and flavor.
\end{abstract}

Keywords: hilsa fish; quality; vacuum packaging; rancid odor

\section{Introduction}

Hilsa fish (Tenualosa ilisha), an anadromous fish migrating from the sea for spawning in freshwater rivers, is an important fishery in some Asian and Middle East countries [1]. Hilsa is Bangladesh's national fish and is highly famous for its delicious taste and unique flavors, and high socioeconomic importance [2,3]. It is economically the most significant single species, employing about 0.45 million people directly, and about 2.5 million people indirectly ([2]. Globally, 86\% of hilsa come from Bangladesh, followed by India (8\%), Myanmar (4\%), and the rest from other countries [3]. Total hilsa production was 0.52 million MT in 2017-2018, sharing $12.09 \%$ of the total fish production in Bangladesh. About $60-70 \%$ of this high demand fish is consumed fresh in Bangladesh, and the rest is exported to India, USA, EU, Japan, and the Middle East [4].

In hilsa fishing, two types of boats are used; larger boats having icing facilities are engaged in fishing for few days to a month, and small boats without icing facilities are engaged in fishing near the shore for few hours to a whole day and fish are iced onshore. As a result, improper onboard icing and without icing, hilsa shad undergoes deteriora- 
tion during this period. On the shore, hilsa fishes are iced in different containers, mostly in Styrofoam boxes and transported in many ways [5,6].

Hilsa fishes are traded in domestic markets as fresh, whole, and without dressing and adding ice. High fat content makes the hilsa fish highly susceptible to oxidative rancidity, along with rapid autolysis and bacteriological decomposition [6]. Therefore, careful handling is necessary at all stages of transportation, processing, preservation, and marketing to control and slow down spoilage [7].

Hilsa cannot be sun-dried due to its high lipid content. Therefore, icing is the most common short-term preservation process, and salting or salt-fermenting is the long-term one. Freezing and frozen storage are also sometimes practiced [8]. However, this long-term frozen storage deteriorates hilsa quality due to the oxidation of lipid and myoglobin's disintegration along the lateral line [9]. Any intervention with freezing is required to retain the quality and flavor for a more extended period. Vacuum packaging, a proven packaging method, could be an effective intervention along with freezing to increase shelf life, which will ensure a year-round supply of quality fish in the market.

\section{Materials and Methods}

Sample collection and preparation: Hilsa fishes weighing $0.8 \pm 0.15 \mathrm{~kg}$ were bought from the hilsa landing center in Chandpur, Bangladesh. The fishes were then brought to the Quality Control Laboratory of the Department of Fisheries at the University of Rajshahi under icing condition. After arriving, half of the fishes were dressed, and half were kept as a whole. In both cases, fishes were washed properly with tap water. Four types of packaging were used as treatments: (a) whole without pack as control, (b) whole with vacuum pack, (c) dressed without pack, and (d) dressed with vacuum pack. Vacuum packaging was done in low oxygen and a moisture permeable plastic pouch (Polyethylene/Polyamide/Polyethylen) using a Multivac C100 packaging unit (Haggenmueller, Germany). A total of 132 fishes (33 in each treatment) were kept separately in frozen storage at $-18{ }^{\circ} \mathrm{C}$ for 12 months. The fishes in triplicate were subjected to biochemical and microbiological analysis at a 30-day interval in the laboratory.

Biochemical and Microbiological Analysis: The $\mathrm{pH}$ of the hilsa fish was determined by using a pH meter (HI2002, Hanna Inst, Woonsocket, RI, USA) [10]. Total volatile base nitrogen (TVB-N) was measured using the European Commission method [11]. Thiobarbituric acid reactive substance (TBARS) was estimated using a colorimetric method [12]. Total viable count (TVC) was determined on plate count agar (Sigma-Aldrich, St. Louis, MO, USA) by standard pour plate method [13] and expressed as colony-forming units (CFU/g). Plates were kept for $48 \mathrm{~h}$ in an incubator (Poleko, Wodzisław Śląski, Poland) at $35^{\circ} \mathrm{C}$ and later colonies were counted.

\section{Results}

\section{1. $\mathrm{pH}$ Value}

In this study, the initial $\mathrm{pH}$ of hilsa fish was 5.55 and then gradually increased until the second month of the storage. The $\mathrm{pH}$ values then fluctuated from 5.84 to 6.50 for samples without pack and 6.00 to 6.57 for vacuum pack fish samples (Figure 1). However, no significant differences $(p>0.05)$ were observed among the treatments during the entire storage period. 


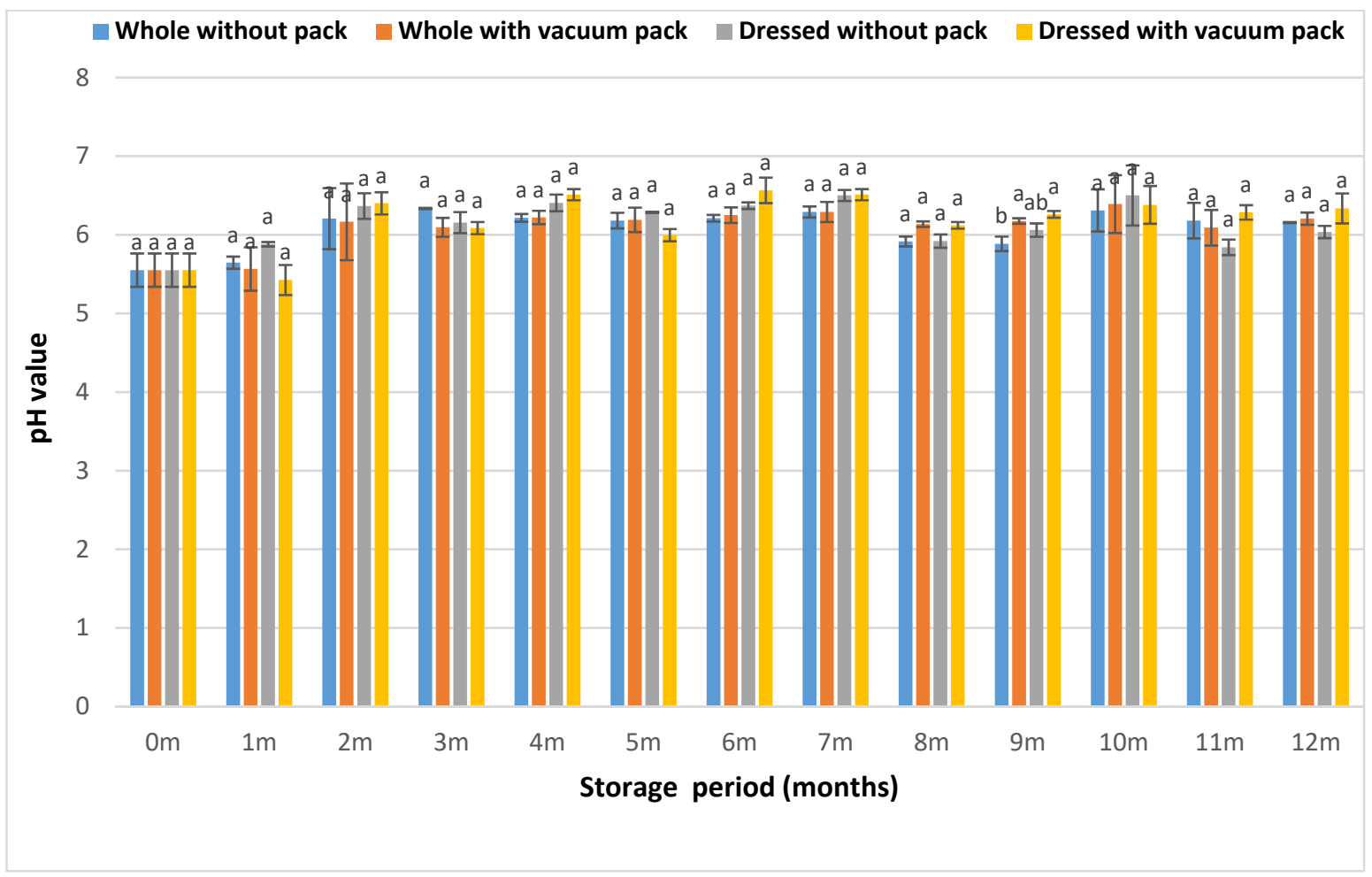

Figure 1. Changes in $\mathrm{pH}$ value of hilsa fish under vacuum packaging conditions during frozen storage. Different letters on the top of each month's bars denote a significant difference among the means of treatments $(p<0.05)$.

\subsection{Total Volatile Base Nitrogen (TVB-N) Value}

The initial TVB-N value was $2.1 \mathrm{mg} / 100 \mathrm{~g}$ and then increased sharply in the first month, and later a decreasing trend with fluctuations was observed until the fourth month for the vacuum pack samples and the fifth month for samples without pack. After that, the TVB-N values in all samples fluctuated during the rest of the storage period. The range of TVB-N value was 1.8 to $5.6 \mathrm{mg} / 100 \mathrm{~g}$ (Figure 2). There was no significant difference $(p>0.05)$ among the treatments until the eight month of storage. However, significantly $(p<0.05)$ lower TVB-N values were observed in dressed fishes than whole fishes on ninth month and later.

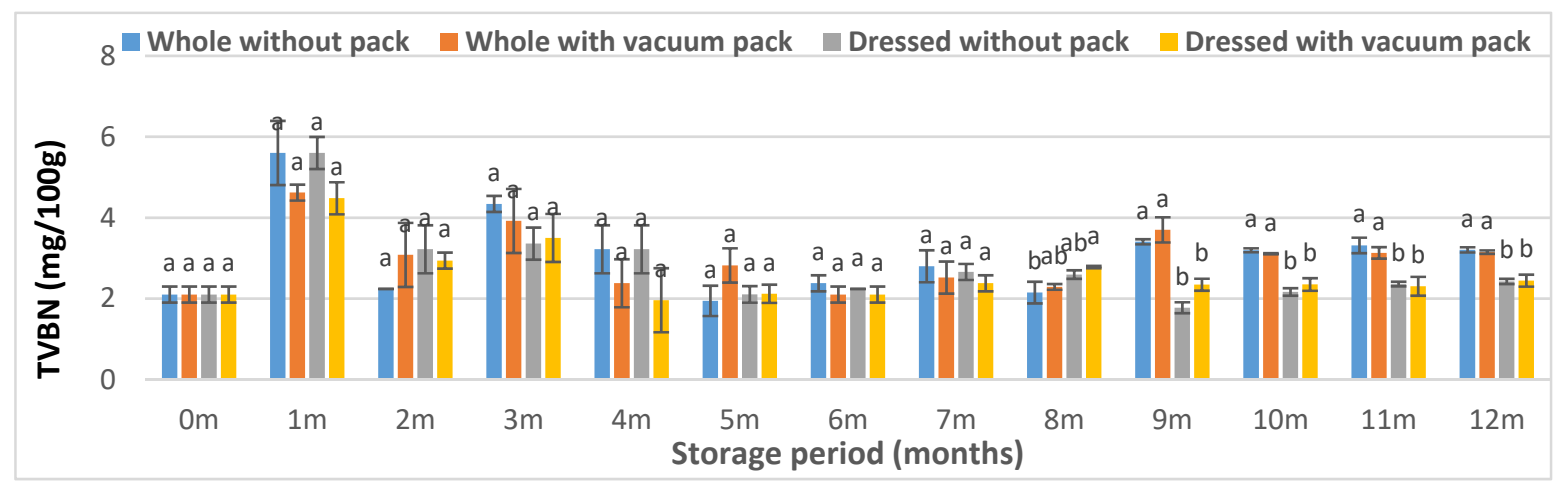

Figure 2. Changes in total volatile base nitrogen (TVBN) value $(\mathrm{mg} / 100 \mathrm{~g})$ of hilsa fish under vacuum packaging conditions during frozen storage. Different letters on the top of each month's bars denote a significant difference among the means of treatments $(p<0.05)$.

\subsection{Free Fatty Acids (FFA)}

The initial FFA value of hilsa fish was $0.46 \%$ oleic acid and then gradually increased to $2.78-3.03 \%$ in the third month and then sharply decreased to $0.32-0.39 \%$ on the fourth 
month, and kept almost steady during rest of the storage (Figure 3). However, there was no significant difference $(p>0.05)$ among the treatments during the entire storage.

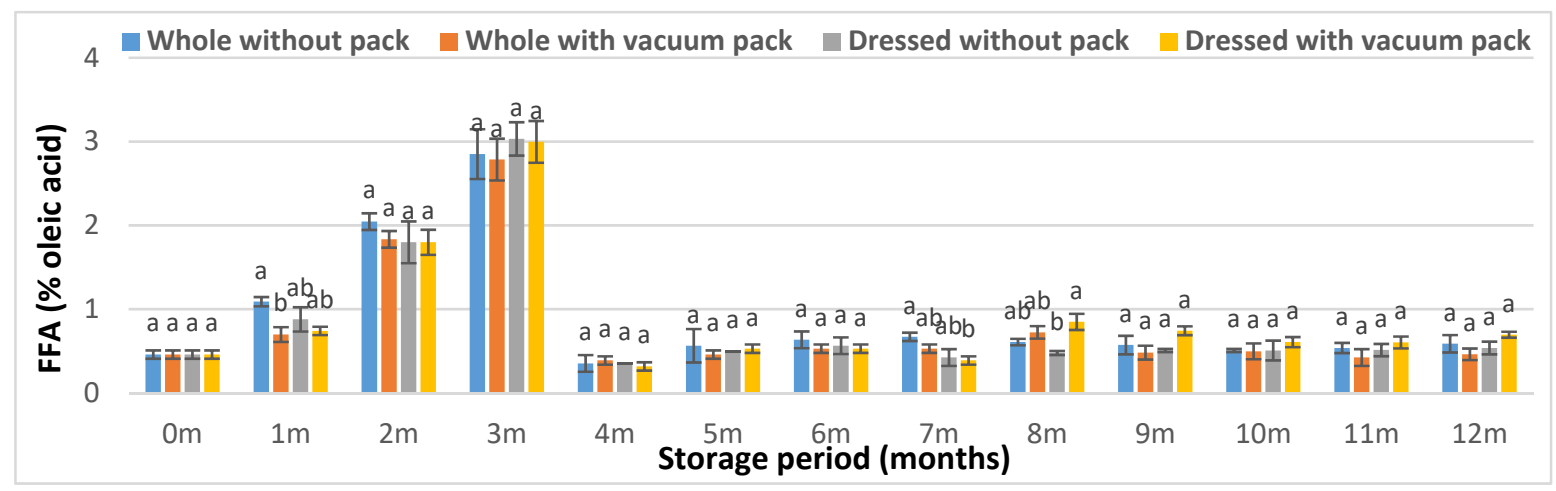

Figure 3. Changes in free fatty acids (FFA) value (\% oleic acid) of hilsa fish under vacuum packaging conditions during frozen storage. Different letters on the top of each month's bars denote a significant difference among the means of treatments $(p<0.05)$.

\subsection{Aerobic Plate Count (APC)}

The aerobic plate count (APC) of fresh hilsa fish was $5.19 \log \mathrm{CFU} / \mathrm{g}$, indicating an acceptable initial quality of hilsa fish. The APC values of hilsa fish gradually increased until the second month and then gradually decreased to around $4.5 \log \mathrm{CFU} / \mathrm{g}$ in the fifth month and remained steady with some fluctuations during the rest of the storage period (Figure 4). However, no significant difference $(p>0.05)$ was observed among the treatments during the storage period.

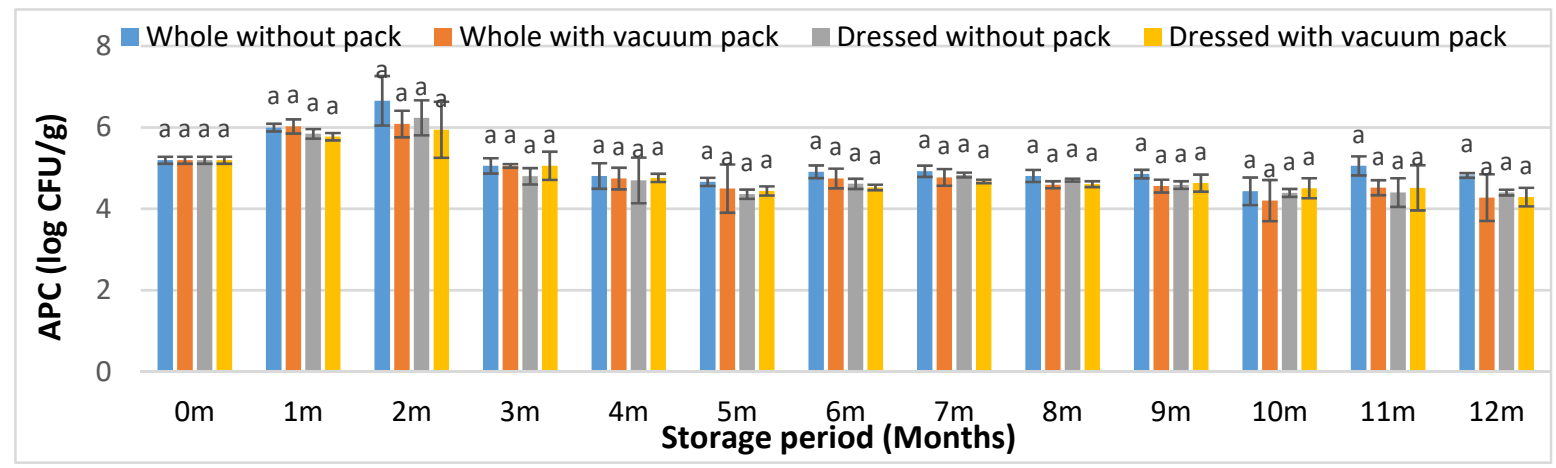

Figure 4. Changes in aerobic plate count (APC) (log CFU/g) of hilsa fish under vacuum packaging condition during frozen storage. Different letters on the top of each month's bars denote a significant difference among the means of treatments $(p<0.05)$.

\subsection{Thiobarbituric Acid Reactive Substance (TBARS) Value}

The initial value of TBARS was $0.79 \mathrm{mg}$ malondialdehyde (MDA)/ $\mathrm{kg}$ of hilsa fish. The TBARS amount gradually increased in the whole fish sample without pack up to the second month and then slowly decreased until the seventh month, and then an increasing trend was observed (Figure 5). In the case of dressed without pack samples, the TBARS value gradually increased up to the third month and then sharply increased to $14.54 \mathrm{mg} \mathrm{MDA} / \mathrm{kg}$ on the fifth month, and later increased slowly with some fluctuations during the rest of the storage period. For vacuum pack samples (whole and dressed), the TBARS amounts fluctuated almost within the acceptable limit during the entire storage period (Figure 5). 


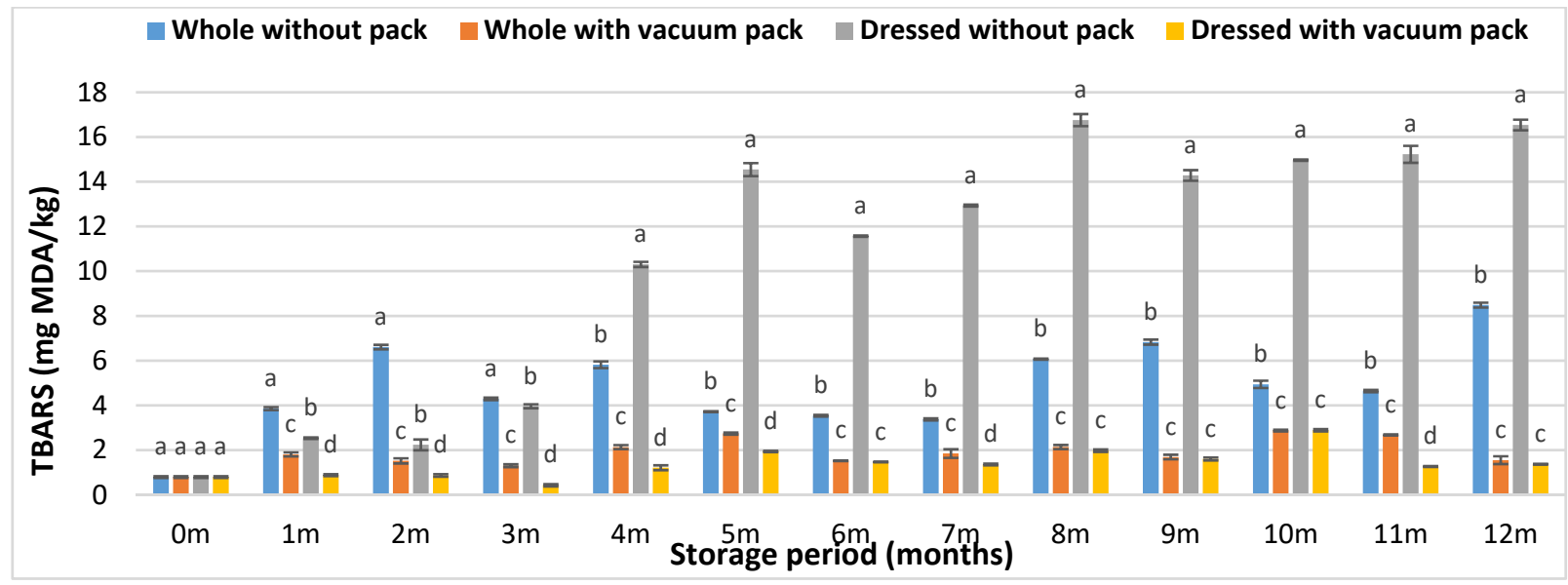

Figure 5. Changes in thiobarbituric acid reactive substance (TBARS) value (mg malondialdehyde/kg) of hilsa fish under vacuum packaging conditions during frozen storage. Different letters on the top of each month's bars denote a significant difference among the means of treatments $(p<0.05)$.

However, TBARS amounts were significantly $(p<0.05)$ affected by the vacuum packaging in both whole and dressed fish during the storage period. Significantly $(p<$ $0.05)$ lower TBARS amounts were found in vacuum pack samples (whole and dressed) compared to the samples without pack during the entire storage period. In addition, significantly $(p<0.05)$ lower TBARS amounts were found in dressed with vacuum pack samples compared to the whole with vacuum pack for most sampling days. In the case of vacuum pack samples, significantly $(p<0.05)$ lower TBARS amounts were observed in whole fish compared to that of dressed fish on the fourth month and later.

\section{Discussion}

The $\mathrm{pH}$ of fish and fishery products provides an evaluation of product quality. The appropriate postmortem $\mathrm{pH}$ level of fish is typically 6.8 7.0 [14]. The $\mathrm{pH}$ values of all samples were within the acceptable limit during the storage period. Increased $\mathrm{pH}$ up to two months could be due to the accumulation of amines and other volatile compounds through the autolytic and microbial activity on proteins and other compounds [15].

TVB-N content is commonly used as an indicator for predicting bacterial spoilage of fish [16]. The TVB-N values of $30-35 \mathrm{mg} \mathrm{N} / 100 \mathrm{~g}$ fish is generally considered an acceptability limit for fresh and ice-stored fish [17]. In the present study, the increasing TVB-N value in the first month could be due to the production of basic compounds via microbiological action on protein and no protein nitrogenous compounds. This initial TVB-N rise corresponds with the increase in $\mathrm{pH}$ up to second month in the present study (Figure 1-2). However, the TVB-N contents of all samples were within the acceptable limit.

FFA is considered to have adverse effects on protein properties; thus, FFA accumulation has been associated with a lack of acceptability and oxidizes faster than higher molecular weight lipid groups [18]. FFA increased during the frozen storage, suggesting that lipid hydrolysis occurred at low temperatures as well (Figure 3). This rise was found to be noticeably higher during the first stage of the experiment (months $0-3$ at $-18{ }^{\circ} \mathrm{C}$ ), which is in line with previous research $[19,20]$. This activity has been explained by a maximum lipase release from liposomes during storage, which allows closer proximity between enzyme and substrate [21]. However, after the initial increase, a similar decreasing trend was observed after the third month for frozen white cheek shark in frozen storage [22]. This decrease may be attributed to the depletion of substrate and oxidation of FFA [23]. In this study, the FFA content of hilsa fishes was within the acceptable limit (5\% oleic acid) during the entire storage [24].

The bacteria counts of 2-6 log CFU/g are considered the satisfactory initial standard of freshly caught freshwater fish [25], which indicated the acceptable initial quality of the 
hilsa fish. In a previous study, the total bacterial count of $5.47 \log \mathrm{CFU} / \mathrm{g}$ was observed in frozen hilsa fish after one month of frozen storage, which is slightly lower than that of the present study [26]. In this study, the APC values did not exceed the $7 \log$ CFU/g [27], considered to be the upper acceptable limit for fresh and frozen fish in all samples over the storage period (Figure 4).

The thiobarbituric acid reactive substances (TBARS) number is a measure of malondialdehyde (MDA), a byproduct of secondary lipid oxidation [28]. A value of $2 \mathrm{mg}$ $\mathrm{MDA} / \mathrm{kg}$ fish is the acceptable limit of TBARS value, and when this limit is exceeded, an obnoxious odor and taste build up in fish [29]. In this study, a gradual increase of TBARS value with storage time was observed in samples without pack. The TBARS values crossed the acceptable limit $(2 \mathrm{mg} \mathrm{MDA} / \mathrm{kg})$ in both whole and dressed samples under without pack samples during the first month and later (Figure 4). A similar increasing trend was observed in narrow barred Spanish mackerel fish, indicating high lipid oxidation [22]. However, in vacuum pack samples, the values were almost within the acceptable limit during the entire storage period (Figure 5). It is assumed that the vacuum packaging could reduce the secondary oxidation of fatty fish like hilsa during the storage period, responsible for the rancid odor in long-term frozen stored hilsa fish. Under frozen storage conditions, vacuum packaging resulted in less oxidative degradation than traditional packaging of frozen cobia fish fillets [30]. In another study, the removal of oxygen from the package was suggested to be more important than the use of antioxidants in delaying lipid oxidation in mackerel fish [31].

\section{Conclusions}

In the present study, the vacuum packaging effectively controlled the TBARS values in both whole and dressed hilsa fishes during the storage period. This study clearly showed that the vacuum packaging prevented the oxidative rancidity in the long-term frozen hilsa fishes. Thus, this vacuum packaging technique can be used along with frozen storage by the processors or even households to make the hilsa fish available year-round without hampering the quality and taste.

Author Contributions: Conceptualization, M.T.I. and M.A.B.; methodology and investigation, S.K., S.A., and Z.N.; investigation, S.K., S.A., and Z.N.; writing-original draft preparation, S.K. and M.T.I.; writing-review and editing, M.M.H. and F.A.F.; supervision, M.T.I. and M.A.B.; project administration, M.A.B. and Y.M. All authors have read and agreed to the published version of the manuscript.

Funding: This research was funded by the Bangladesh Fisheries Research Institute (BFRI) under the Strengthening of Hilsa Research in Riverine Station Chandpur Project (grant no.-6).

Institutional Review Board Statement: Not applicable for studies not involving human or animals.

Informed Consent Statement: Not applicable for studies not involving humans.

Data Availability Statement: Data are publicly available.

Conflicts of Interest: The authors declare no conflict of interest.

\section{References}

1. Hossain, M.S.; Sharifuzzaman, S.M.; Rouf, M.A.; Pomeroy, R.S.; Hossain, M.D.; Chowdhury, S.R.; AftabUddin, S. Tropical Hilsa Shad (Tenualosa Ilisha): Biology, Fishery and Management. Fish Fish. 2019, 20, 44-65, doi:10.1111/faf.12323.

2. Rahman, M.J.; Wahab, M.A.; Nahiduzzaman, M.; Haque, A.B.M.M.; Cohen, P. Hilsa Fishery Management in Bangladesh. In IOP Conference Series: Earth and Environmental Science; IOP: Bristol, UK, 2020; Volume 414, doi:10.1088/1755-1315/414/1/012018.

3. Rahman, M.J.; Wahab, M.A.; Amin, S.M.N.; Nahiduzzaman, M.; Romano, N. Catch Trend and Stock Assessment of Hilsa Tenualosa Ilisha Using Digital Image Measured Length-Frequency Data. Mar. Coast. Fish. 2018, 10, 386-401, doi:10.1002/mcf2.10034.

4. DoF. Yearbook of Fisheries Statistics of Bangladesh, 2017-18; Fisheries Resources Survey System (FRSS), Department of Fisheries; Ministry of Fisheries: Dhaka, Bangladesh, 2018. 
5. Nowsad, A.K.M.A. Report on Landing Center Monitoring -A Survey Research in Collaboration with Bangladesh Center for Advanced Studies and Center for Natural Resources Studies. ECFC Field Rep-5; FAO: Dhaka, Bangladesh, 2004.

6. Nowsad, A.K.M.A. Post-Harvest Loss Reduction in Fisheries in Bangladesh: A Way Forward to Food Security. Final Report. NFPCSP-FAO, PR\#5/08 Project; FAO: Dhaka, Bangladesh, 2010.

7. Alam, A.K.M.; Mohanty, B.P.; Hoq, M.E.; Thilsted, S. Nutritional Values, Consumption and Utilization of Hilsa. In Hilsa: Status of Fishery and Potential for Aquaculture. Penang, Malaysia: WorldFish. Proceedings: 2019-16; Wahab, M.A., Beveridge, M.C.M., Phillips, M.J., Eds.; WorldFish: Penang, Malaysia, 2012; pp. 159-187, 196p.

8. Nowsad, A.K.M.A. Participatory Training of Trainers: A New Approach Applied in the Fish Processing; Bangladesh Fisheries Research Forum: Dhaka, Bangladesh, 2007.

9. Clucas, I.J., Ward, A.R. Post-Harvest Fisheries Development: A Guide to Handling, Preservation, Processing and Quality; Natural Resources Institute (NRI): Chatham, UK, 1996.

10. Binsi, P.K.; Viji, P.; Visnuvinayagam, S.; Ninan, G.; Sangeeta, G.; Triveni, A.; Ravishankar, C.N. Microbiological and Shelf Life Characteristics of Eviscerated and Vacuum Packed Freshwater Catfish (Ompok Pabda) during Chill Storage. J. Food Sci. Technol. 2015, 52, 1424-1433, doi:10.1007/s13197-013-1165-x.

11. EC. Determination of the Concentration of TVB-N in Fish and Fishery Products. Commission Regulation, Chapter III. (EC) No 2074/2005. Off. J. Eur. Union 2005, L338, 37-39.

12. Park, S.Y.; Yoo, S.S.; Uh, J.H.; Eun, J.B.; Lee, H.C.; Kim, Y.J.; Chin, K.B. Evaluation of Lipid Oxidation and Oxidative Products as Affected by Pork Meat Cut, Packaging Method, and Storage Time during Frozen Storage (-10 ${ }^{\circ}$ C). J. Food Sci. 2007, 72, 114-119, doi:10.1111/j.1750-3841.2006.00265.x.

13. APHA. Compendium of Methods for the Microbiological Examination of Foods, 3rd ed.; Vanderzant, C., Splittstoesser, D.F., Ed.; American Public Health Association: Washington, DC, USA, 1992.

14. Metin, S.; Erkan, N.; Varlik, C.; Aran, N. Extension of Shelf-Life of Chub Mackerel (Scomber Japonicus Houttuyn 1780) Treated with Lactic Acid. Eur. Food Res. Technol. 2001, 213, 174-177, doi:10.1007/s002170100362.

15. Binsi, P.K.; Shamasundar, B.A.; Dileep, A.O. Physico-Chemical and Functional Properties of Proteins from Green Mussel (Perna Viridis) during Ice Storage. J. Sci. Food Agric. 2007, 87, 245-254, doi:10.1002/jsfa.2706.

16. Wu, T.H.; Bechtel, P.J. Ammonia, Dimethylamine, Trimethylamine, and Trimethylamine Oxide from Raw and Processed Fish by-Products. J. Aquat. Food Prod. Technol. 2008, 17, 27-38, doi:10.1080/10498850801891140.

17. Connell, J.J. Control of Fish Quality, 4th ed.; Wiley-Blackwell: Oxford, UK, 1995.

18. Sikorski, Z.E.; Kołakowska, A. Changes in Proteins in Frozen Stored Fish. In Seafood Proteins; Springer: Berlin/Heidelberg, Germany, 1994; pp. 99-112, doi:10.1007/978-1-4615-7828-4_8.

19. Rodríguez, A.; Losada, V.; Larraín, M.A.; Quitral, V.; Vinagre, J.; Aubourg, S.P. Development of Lipid Changes Related to Quality Loss during the Frozen Storage of Farmed Coho Salmon (Oncorhynchus Kisutch). JAOCS J. Am. Oil Chem. Soc. 2007, 84, 727-734, doi:10.1007/s11746-007-1098-5.

20. Aubourg, S.P.; Rodríguez, A.; Gallardo, J.M. Rancidity Development during Frozen Storage of Mackerel (Scomber Scombrus): Effect of Catching Season and Commercial Presentation. Eur. J. Lipid Sci. Technol. 2005, 107, 316-323, doi:10.1002/ejlt.200401124.

21. Sikorski, Z.; Kolakowski, E. Endogenous Enzyme Activity and Seafood Quality: Influence of Chilling, Freezing, and Other Environmental Factors. In Seafood Enzymes; Simpson, H., Ed.; Marcel Dekker: New York, NY, USA, 2000; pp. $451-487$.

22. Nazemroaya, S.; Sahari, M.A.; Rezaei, M. Effect of Frozen Storage on Fatty Acid Composition and Changes in Lipid Content of Scomberomorus Commersoni and Carcharhinus Dussumieri. J. Appl. Ichthyol. 2009, 25, 91-95, doi:10.1111/j.1439-0426.2008.01176.x.

23. Namulema, A.; Muyonga, J.H.; Kaaya, A.N. Quality Deterioration in Frozen Nile Perch (Lares Niloticus) Stored at -13 and -27 ${ }^{\circ}$ C. Food Res. Int. 1999, 32, 151-156, doi:10.1016/S0963-9969(99)00066-6.

24. Bimbo, A.P. Guidelines for Characterizing Food-Grade Fish Oil. Inf. Int. News Fats Oils Relat. Mater. 1998, 9, $473-483$.

25. Gelman, A.; Glatman, L.; Drabkin, V.; Harpaz, S. Effects of Storage Temperature and Preservative Treatment on Shelf Life of the Pond-Raised Freshwater Fish, Silver Perch (Bidyanus Bidyanus). J. Food Prot. 2001, 64, 1584-1591, doi:10.4315/0362-028X-64.10.1584.

26. Shamsuzzaman, M.; Mazumder, S.; Siddique, M.; Miah, M. Microbial Quality of Hilsa Shad (Tenualosa Ilisha) at Different Stages of Processing. J. Bangladesh Agric. Univ. 2012, 9, 339-344, doi:10.3329/jbau.v9i2.11049.

27. ICMSF. Microorganisms in Foods 2: Sampling for Microbiological Analysis: Principles and Specific Applications, 2nd ed.; University of Toronto Press: Toronto, AB, Canada, 1986; doi:10.2307/1268642.

28. Bremner, H.A. Safety and Quality Issues in Fish Processing. J. Aquat. Food Prod. Technol. 2003, 12, 83, doi:10.1300/J030v12n03_08.

29. Connell, J.J. Control of Fish Quality, 3rd ed.; Fishing News Books: Oxford, UK, 1990.

30. Taheri, S.; Motallebi, A.A. Influence of Vacuum Packaging and Long Term Storage on Some Quality Parameters of Cobia (Rachycentron canadum) Fillets during Frozen Storage. Am. J. Agric. Environ. Sci. 2012, 12, 541-547.

31. Santos, E.E.M.; Regenstein, J.M. Effects of Vacuum Packaging, Glazing, and Erythorbic Acid on the Shelf-Life of Frozen White Hake and Mackerel. J. Food Sci. 1990, 55, 64-70, doi:10.1111/j.1365-2621.1990.tb06017.x. 